\title{
CORRELATION OF STRUCTURE AND FUNCTION IN THE HANDLING OF GLUCOSE BY THE NEPHRONS OF THE CANINE KIDNEY*
}

\author{
By S. E. BRADLEy, J. H. LARAGH, H. O. WHEELER $\dagger$, M. MacDOWELL and \\ J. OLIVER \\ (From the Department of Medicine, Columbia University College of Physicians and Surgeons, \\ New York, N. Y. and the Renal Research Unit, Research Department, CIBA \\ Pharmaceutical Products, Inc., Summit, N. J.)
}

(Submitted for publication November 18, 1960; accepted March 9, 1961)

The mammalian kidney presents a variety of almost self-evident correlations between structure and function. The glomerulus, with its enclosed capillary tuft, is obviously designed to serve as a filtering unit. The tubular systems draining the glomeruli are likewise clearly organized in such a way as to process most efficiently the filtrate formed in the glomeruli during its passage to the bladder. Numerous studies, both direct and indirect, have proved that processing of filtrate involves reabsorption and secretion by the tubule cells and that it depends upon an orderly arrangement of sequential processes at different levels in the tubules. Since all nephrons are similar in construction, renal function may be conceived in terms of a single unit and interpreted in terms of the basic anatomical arrangement.

The uniformity of nephron construction, however, is coupled with a dimensional heterogeneity (1). This fact would seem to preclude functional homogeneity and to indicate an equally diverse composition and volume of urine formed by different nephrons. In addition to variation in size, the nephron population is subjected to further variability through its dependence upon the circulatory system. Filtration is, in the last analysis, a circulatory phenomenon. As such, it is affected both by vascular adjustments involved in the regulation of urine formation and by general systemic responses. Nevertheless, a growing body of evidence suggests that over-all function may be a valid guide to function of the individual nephron under basal conditions, suggesting that filtration is evenly distributed and that anatomical variation is minimized in some manner.

* This work was supported by a grant from the New York Heart Association (SEB) and by Grant H-3765-C1 (J0) from the National Heart Institute, Bethesda, Md.

$\dagger$ John and Mary Markle Scholar in Medical Science.
Theoretically, the range of nephron activity could be restricted by a balanced relationship between glomeruli and tubules that would assure uniform loading of tubular cells, a relationship that might lend itself to structural-functional correlation. The volume of filtrate formed in any glomerulus each minute must be determined by capillary filtration pressure and the capillary surface area available for filtration. The afferent arteriolar resistance is believed to be relatively low so that glomerular capillary pressure approximates mean arterial pressure throughout the kidney. Hence, differences in glomerular size may be assumed to reflect corresponding differences in filtration and in the load imposed upon the dependent tubule. Since glomerulotubular balance implies a uniformity in the distribution of filtered load to tubular cells, it follows that balance may be expressed structurally as a proportionality between certain glomerular and tubular dimensions.

Although a physiological concept, glomerulotubular balance is not easily defined on the basis of function alone. Glomerular filtration and tubular function can be measured only for the entire kidney, not for individual nephrons. For this purpose Smith and associates (2) have devised a method of measuring tubular glucose reabsorption relative to filtered load at successively higher plasma glucose levels (glucose titration) that permits characterization of the population of nephrons in the distribution of "glomerular activity"; i.e., glomerular filtration rate relative to the maximal tubular glucose reabsorptive capacity of the attached tubule $\left(c_{\mathrm{in}} / \mathrm{tm}_{\mathrm{g}}\right)$. If all nephrons had the same glomerular activity, all filtered glucose would be reabsorbed at all plasma levels up to that at which the glucose transfer mechanism is saturated; thereafter the rate of reabsorption would be constant (glucose Tm) and the glucose filtered in ex- 
cess of the transfer maximum would escape in the urine. Such an ideal situation rarely, if ever, obtains because glomerular activity varies within the nephron population so that glucose appears in the urine at filtered loads well below Tm levels and loads greatly in excess of $\mathrm{Tm}$ are required to assure saturation of the whole kidney. The resulting departure or "splay" from the ideal straight line relationship between tubular reabsorption and load is thus an expression of the degree and kind of dispersion of glomerular activity, or glomerulotubular balance, in the nephron population. From functional data of this kind it is possible to predict a close correlation between glomerular and tubular dimensions that may be related respectively to filtration and to the maximal glucose reabsorptive capacity.

This prediction has been verified by Oliver and MacDowell (3) in the course of studies of the dimensions of the nephron population in normal human kidneys. The diameter, volume and surface area of the glomeruli, and the length and volume of their attached proximal convoluted tubules were measured directly in 104 nephrons carefully dissected from kidneys of three normal human subjects killed by accidents. No correlation was observed between glomerular surface and proximal length or between glomerular volume and proximal length. A definite tendency for proximal volume and the glomerular volume to vary in the same direction was evident. Glomerular surface, however, was found to be closely and significantly correlated with proximal volume. In view of the fact that glucose reabsorption is limited to the proximal convoluted tubule (4), this relationship seemed to justify the inference that the functional correlation between individual nephron glomerular filtration rate and its tubular glucose reabsorptive capacity might be best expressed in measurable structural terms by the ratio between glomerular surface and proximal convoluted tubular volume. Accepting these measurements as structural-functional equivalents, it is possible to predict the extent to which such a glomerular surface-proximal volume correlation might bring about a deviation in the titration curve from the predicted straight line relationships. When this was done, it was found that the functional data obtained in man by Smith and his coworkers quite closely fitted the curve derived from the structural measurements, indicating that splay may indeed be regarded as evidence of a dispersion of structural glomerulotubular balance. To evaluate this relationship more closely, a measurement of glucose titration was made in dogs and compared with curves derived from anatomical data obtained subsequently in the same animals.

\section{METHODS}

Three trained, adult, female dogs were used as the subjects of this study. All were mongrels in good health. Dali, a Dalmatian, weighed $23 \mathrm{~kg}$; Cora, predominantly a Boxer, weighed $19 \mathrm{~kg}$; Elena, a miniature Collie, weighed $15 \mathrm{~kg}$. Each was studied on at least four occasions at intervals of 2 to 3 weeks over a total period ranging from 6 to 13 weeks. In each determination arterial blood samples were obtained at approximately 30 minute intervals by an indwelling needle inserted into the femoral artery. Urine was collected by an indwelling catheter at approximately 10-minute intervals before and during intravenous infusion of inulin and glucose. All urine samples were obtained continuously, and emptying was assured by manual expression and $15-\mathrm{ml}$ saline washouts. Intravenous infusion of inulin and glucose was maintained at a constant rate by a motor-driven pump (Bowman). The animals were studied in a fasting condition after adequate hydration. Moreover, isotonic saline was usually infused rapidly prior to beginning measurements in order to assure adequate urine flow. Mannitol was frequently added to the "priming" doses of inulin for the same purpose. After the administration of glucose and the appearance of high glucose blood concentrations, continuous diuresis developed and high urine flows were achieved. The dogs were given no premedication or sedation. They were trained to lie quietly throughout the procedure, but every effort was made to avoid discomfort and pain. For this purpose procaine was infiltrated about the point of needle insertions and the catheter was manipulated as little as possible. Urine samples were collected and the bladder washed out gently in order to avoid discomfort or trauma. At no time did any evidence of urinary tract infection develop, and the dogs remained in good health and good spirits throughout.

Glomerular filtration was measured by inulin clearance (5) rather than creatinine clearance, since creatinine could not be determined with sufficient accuracy in the presence of high plasma glucose levels. A small priming dose, up to $1 \mathrm{~g}$ of inulin, was administered at the beginning of each infusion after quantitative collection of urine over a measured period of time in order to provide a value for "blank" excretion. An inulin infusion was made up in concentrations designed to provide 14 to $20 \mathrm{mg}$ per minute of inulin continuously (in $2.5 \mathrm{ml}$ per minute) throughout the study. Inulin was determined in cadmium filtrates (6) of plasma and in diluted urine by the Harrison method (7).

Various methods were employed to raise the plasma 
glucose concentration gradually from the control values to levels well in excess of those necessary to saturate the transfer mechanisms. In most instances 2 to 3 collection periods of urine were obtained prior to the addition to the infusion of glucose ( 50 per cent solution) and sufficient supplementary inulin to assure maintenance of the inulin concentration in the infusion. Glucose and appropriate amounts of inulin were added at approximately three period intervals thereafter to raise the plasma glucose levels. As a rule (see Results for additional details), a large amount of glucose was administered intravenously at the end of each study to guarantee establishment of high plasma glucose concentrations. Urine was discarded for approximately 30 minutes thereafter to permit equilibration of the plasma level and to eliminate artifact resulting from a rapidly changing excretion. The plasma and urinary glucose concentrations were measured in cadmium filtrates of plasma in diluted urine by the Nelson-Somogyi method (8) and appropriate corrections were made for urinary and plasma "blanks." To assure accuracy of results, determinations were made immediately after collection of the urine and plasma samples.

When enough data had been accumulated to permit evaluation of the titration curve, the left kidney was removed surgically from each animal, weighed, and fixed in 10 per cent formalin. As far as could be determined from gross and microscopic examination, there was no evidence in any of renal disease. Small blocks of tissue which included the cortex and medulla were excised from the kidney at uniformly distributed points. These blocks were then allowed to undergo maceration for 40 to 48 hours in concentrated $\mathrm{HCl}$; thereafter, the nephrons were separated in water with needles under a binocular microscope. Complete proximal convolutions ${ }^{1}$ with their attached glomeruli were isolated randomly from each block-that is, in equal numbers from beneath the capsular surface, from the mid-cortex, and from the lowermost level of the cortex. The isolated nephrons were floated onto a slide in a drop of water and after gentle manipulation they spread out sufficiently to permit camera lucida drawings from which linear measurements could be made. The diameter of the proximal convoluted tubule was measured directly with a filar micrometer at a magnification of $50 \times$, at 10 points evenly distributed along the course of the tubule. These values were averaged and the volume of the tubule was computed as for a cylinder. The greatest and the least diameters of the glomeruli were also measured with the micrometer, averaged, and the surface calculated as for a sphere. Every precaution was taken to avoid swelling and shrinkage (3). The statistical uniformity of the data obtained from repeated dissections over an extended pe-

1 The proximal convoluted tubule may be characterized structurally as that portion of the nephron which extends from the glomerulus to terminate in the outer stripe of the medulla at the transition to the thin portion of Henle's loop. Its first half is convoluted and lies in the cortex; its second half is relatively straight and lies in the medulla. riod strongly suggests that such changes did not affect the results.

\section{RESULTS}

Renal functional parameters. The data obtained in the course of repeated measurements of glomerular filtration rate and tubular reabsorption of glucose in the three dogs are presented in Tables I to III. Both filtration and glucose Tm varied remarkably little in each animal during the period of weeks (up to 13 ; Dali) throughout which the measurements were made. Thus the means for each, computed from the averages for each experiment, did not differ significantly from those based upon the pooled data. The latter are referred to in what follows below. The differences observed between the average figures appear to be determined largely by differences in animal size, although differences in breed cannot be excluded as an influential factor. The values for mean glomerular filtration rate per kilogram of body weight fell within the normal range defined by Houck (9) (Cora, $3.33 \mathrm{ml} / \mathrm{min} / \mathrm{kg}$; Dali, 4.23; Elena, 4.42; as compared with $4.29 \pm \mathrm{SD} 1.01$ for the normal). Maximal glucose reabsorption also tended to vary with body weight; the highest values occurred in Dali (23 kg, $16 \mathrm{mg} / \mathrm{min} / \mathrm{kg}$ ), the lowest in Elena (15 kg, $11.1 \mathrm{mg} / \mathrm{min} / \mathrm{kg}$ ), with intermediate figures in Cora (19 kg, 12.0 $\mathrm{mg} / \mathrm{min} / \mathrm{kg}$ ). Nevertheless, certain discrepancies were evident. The value for glucose Tm was unusually large in Dali, actually greater than the average for a man weighing three times as much, but it was consistent with the filtration rate. The ratios between mean filtration and glucose $\mathrm{Tm}$ in Dali and Cora agreed closely (Dali, $0.263 \mathrm{ml} / \mathrm{mg}$; Cora, 0.278). Perhaps because filtration was relatively high and glucose $\mathrm{Tm}$ somewhat low, the filtration/Tm ratio was much greater $(0.4)$ in the smallest dog, Elena, than in either of the others.

The absence of significant variation in renal function from day to day during the period of observation was consistent with relative stability of the physiological, nutritional, behaviorial, and environmental conditions. During each experiment, moreover, very little change occurred in filtration, presumably because each animal was well trained and well adjusted to a procedure which was designed to avoid undue stimulation. The use of an indwelling arterial needle for the 
Table I

Glomerular Filtration Rate and Tubular Reabsorption of Glucose in the Dog

Core - Body Weight, $19 \mathrm{kgs}$.

\begin{tabular}{|c|c|c|c|c|c|c|c|}
\hline $\begin{array}{l}\mathrm{v} \\
\mathrm{ml} / \mathrm{min}\end{array}$ & $\begin{array}{l}\text { G.F.R. } \\
\mathrm{ml} / \min \end{array}$ & $\begin{array}{l}P_{G} \\
\mathrm{mg} / 100 \mathrm{ml}\end{array}$ & $\begin{array}{l}\text { Filtered } \\
\text { Load } \\
\mathrm{mg} / \mathrm{min}\end{array}$ & $\begin{array}{l}\mathrm{U}_{\mathrm{G}} \mathrm{V} \\
\mathrm{mg} / \mathrm{min}\end{array}$ & $\begin{array}{l}\mathrm{T}_{\mathrm{G}} \\
\mathrm{mg} / \mathrm{min}\end{array}$ & Loed/Tm & T/Tm \\
\hline \multicolumn{8}{|c|}{$10 / 28 / 57$} \\
\hline $\begin{array}{l}0.1 \\
0.1 \\
0.1 \\
0.1 \\
0.2 \\
0.2 \\
0.3 \\
3.6 \\
4.8\end{array}$ & $\begin{array}{l}64 \\
63 \\
57 \\
58 \\
55 \\
70 \\
57 \\
59 \\
65\end{array}$ & $\begin{array}{l}201 \\
204 \\
205 \\
205 \\
201 \\
198 \\
212 \\
640 \\
650\end{array}$ & $\begin{array}{l}128 \\
128 \\
117 \\
120 \\
111 \\
139 \\
121 \\
374 \\
425\end{array}$ & $\begin{array}{r}0.8 \\
0.9 \\
0.8 \\
0.9 \\
0.8 \\
0.9 \\
0.9 \\
145.5 \\
216.3\end{array}$ & $\begin{array}{l}127 \\
127 \\
116 \\
119 \\
110 \\
138 \\
120 \\
229^{+} \\
209^{+}\end{array}$ & $\begin{array}{l}0.57 \\
0.57 \\
0.52 \\
0.53 \\
0.49 \\
0.61 \\
0.54 \\
1.66 \\
1.88\end{array}$ & $\begin{array}{l}0.56 \\
0.56 \\
0.51 \\
0.53 \\
0.49 \\
0.61 \\
0.53 \\
1.01 \\
0.93\end{array}$ \\
\hline Mean & (61) & & & & (219) & & \\
\hline \multicolumn{8}{|c|}{$11 / 20 / 57$} \\
\hline $\begin{array}{l}0.2 \\
0.1 \\
0.1 \\
0.2 \\
0.3 \\
0.5 \\
1.4 \\
1.9\end{array}$ & $\begin{array}{l}64 \\
60 \\
59 \\
75 \\
64 \\
60 \\
61 \\
66\end{array}$ & $\begin{array}{l}178 \\
198 \\
217 \\
235 \\
258 \\
315 \\
383 \\
560\end{array}$ & $\begin{array}{l}115 \\
117 \\
128 \\
176 \\
164 \\
188 \\
234 \\
367\end{array}$ & $\begin{array}{r}0.8 \\
0.7 \\
0.7 \\
1.1 \\
0.9 \\
6.3 \\
10.7 \\
140.0\end{array}$ & $\begin{array}{l}114 \\
116 \\
127 \\
175 \\
163 \\
182 \\
224 \\
227^{+}\end{array}$ & $\begin{array}{l}0.51 \\
0.52 \\
0.57 \\
0.78 \\
0.72 \\
0.83 \\
1.04 \\
1.62\end{array}$ & $\begin{array}{l}0.51 \\
0.51 \\
0.57 \\
0.78 \\
0.72 \\
0.81 \\
0.99 \\
1.01\end{array}$ \\
\hline Mean & (63) & & & & (227) & & \\
\hline
\end{tabular}

III $\overline{11 / 25 / 57}$

$\begin{array}{llllllll}0.9 & 55 & 166 & 91 & 0.6 & 91 & 0.42 & 0.42 \\ 0.9 & 57 & 174 & 99 & 0.7 & 99 & 0.44 & 0.44 \\ 0.7 & 55 & 186 & 103 & 0.7 & 102 & 0.46 & 0.45 \\ 0.8 & 56 & 255 & 144 & 0.8 & 143 & 0.64 & 0.63 \\ 0.8 & 69 & 345 & 238 & 7.4 & 231 & 1.05 & 1.02 \\ 1.1 & 61 & 415 & 271 & 46.7 & 224^{+} & 1.20 & 0.99 \\ 1.3 & 67 & 450 & 294 & 66.6 & 227^{+} & 1.30 & 1.01 \\ 1.4 & 63 & 490 & 320 & 83.8 & 236^{+} & 1.42 & 1.04 \\ 1.3 & 67 & 498 & 325 & 85.9 & 239^{+} & 1.44 & 1.06 \\ 1.3 & 69 & 505 & 330 & 87.6 & 242^{+} & 1.46 & 1.07\end{array}$

IV

Mean (62)

IV $12 / 18 / 57$

\begin{tabular}{|c|c|c|c|c|c|c|c|}
\hline $\begin{array}{l}0.4 \\
0.7 \\
1.0 \\
1.5 \\
2.2 \\
3.2\end{array}$ & $\begin{array}{l}66 \\
64 \\
63 \\
66 \\
64 \\
68 .\end{array}$ & $\begin{array}{l}305 \\
410 \\
432 \\
433 \\
420 \\
401\end{array}$ & $\begin{array}{l}201 \\
261 \\
272 \\
285 \\
270 \\
272\end{array}$ & $\begin{array}{r}9.4 \\
29.7 \\
44.8 \\
51.1 \\
54.0 \\
55.4\end{array}$ & $\begin{array}{l}192 \\
231^{+} \\
227^{+} \\
233^{+} \\
216^{+} \\
217^{+}\end{array}$ & $\begin{array}{l}0.89 \\
1.16 \\
1.21 \\
1.26 \\
1.20 \\
1.20\end{array}$ & $\begin{array}{l}0.85 \\
1.02 \\
1.01 \\
1.03 \\
0.96 \\
0.96\end{array}$ \\
\hline Mean & (66) & & & & (224) & & \\
\hline \multicolumn{8}{|c|}{$\overline{1 / 6 / 58}$} \\
\hline $\begin{array}{l}0.2 \\
0.2 \\
0.3 \\
0.4 \\
0.4 \\
0.5 \\
0.8 \\
1.0 \\
1.6 \\
2.2 \\
2.8\end{array}$ & $\begin{array}{l}52 \\
59 \\
63 \\
70 \\
64 \\
62 \\
67 \\
66 \\
69 \\
73 \\
69\end{array}$ & $\begin{array}{l}160 \\
199 \\
250 \\
290 \\
303 \\
305 \\
305 \\
307 \\
309 \\
309 \\
307\end{array}$ & $\begin{array}{r}83 \\
118 \\
157 \\
204 \\
195 \\
189 \\
204 \\
202 \\
214 \\
226 \\
212\end{array}$ & $\begin{array}{l}0.7 \\
0.8 \\
1.2 \\
1.8 \\
2.5 \\
2.5 \\
2.4 \\
2.4 \\
3.7 \\
5.5 \\
5.4\end{array}$ & $\begin{array}{r}82 \\
117 \\
156 \\
202 \\
192 \\
186 \\
202 \\
199 \\
210 \\
220 \\
208\end{array}$ & $\begin{array}{l}0.37 \\
0.52 \\
0.70 \\
0.90 \\
0.86 \\
0.84 \\
0.90 \\
0.90 \\
0.95 \\
1.90 \\
0.94\end{array}$ & $\begin{array}{l}0.36 \\
0.52 \\
0.69 \\
0.90 \\
0.85 \\
0.82 \\
0.90 \\
0.88 \\
0.93 \\
0.97 \\
0.92\end{array}$ \\
\hline Meen & (65) & & & & & & \\
\hline $\begin{array}{l}\text { N } \\
\text { Moan } \\
\text { S.D. }\end{array}$ & $\begin{array}{l}44 \\
63.2 \\
\pm 5.22\end{array}$ & & & & $\begin{array}{c}13 \\
227.5 \\
\pm 7.99\end{array}$ & & \\
\hline
\end{tabular}

- Urine flow (v), glomerular filtration rate (G.F.R.-inulin clearance), arterial plesme glucose concentration $\left(P_{G}\right)$, filtered load of glucose reaching the tubule (computed os the product $P_{G}$ ) $G$ FR) the urinery output of complo and tubular roabsorption of slucose $\mathrm{I}_{\mathrm{G}}$ - Illtered load loss $\mathrm{U}_{\mathrm{GV}}$ ) are presented hela theses aro avoragos or GN and $\mathrm{TM}_{G}$ for oach oxporimt and thoso at tho poot tho tablo aro the numer (N) of valuos usod to oomputo tho mon and standard

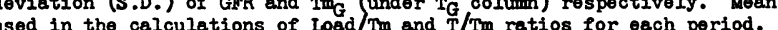

+ Velues at which the maximal rate of glucose reabsorption was obtained ( $P_{G}$ in excess of 400 mg per cent) for use in computation of mean Tma 
collection of blood samples and gentle handling during bladder-emptying were apparently successful in eliminating the renal vasoconstrictive responses which had undoubtedly occurred transiently at the beginning of each test when needles and catheter were put in place. "Discard periods" up to an hour in length were employed to prevent reflection of these reactions in the experimental data. The inulin clearance averaged $97.3 \pm(\mathrm{SD})$ $11.40 \mathrm{ml}$ per minute in Dali, $66.3 \pm 5.96$ in Elena, and $63.2 \pm 5.22$ in Cora, the corresponding coefficients of variation amounting to 11.7, 9.0,

Teble II

Glomerular Filtration Rate and Tubular Reabsorption of Glucose in the Dog

Dali - Body Weight, 23 kgs.

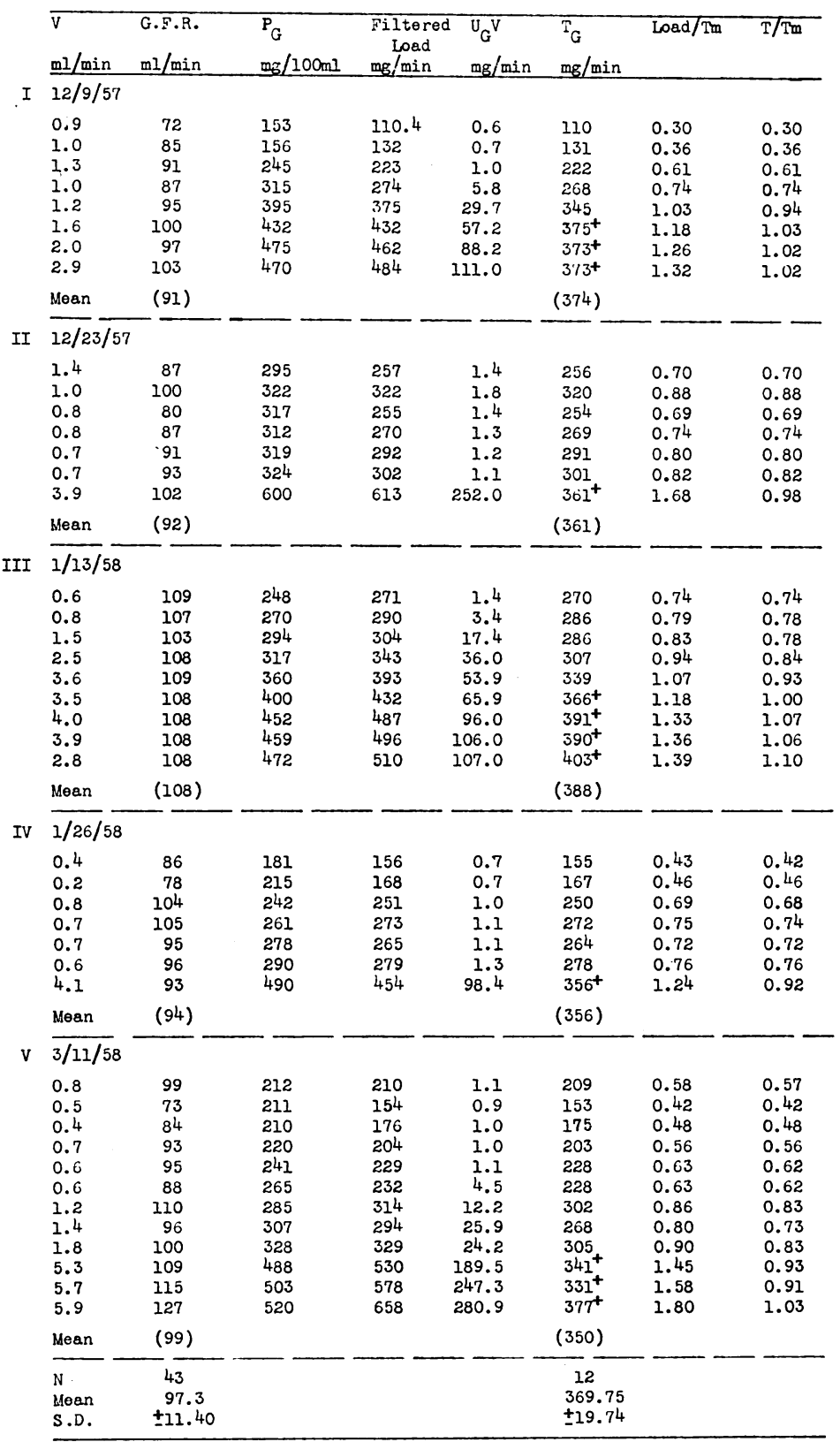

and + - See Footnotes, Table I. 
Table III

Glomerular Filtration Rate and Tubular Reabsorption of Glucose in the Dog"

Elena - Body Weight, $15 \mathrm{kgs}$.

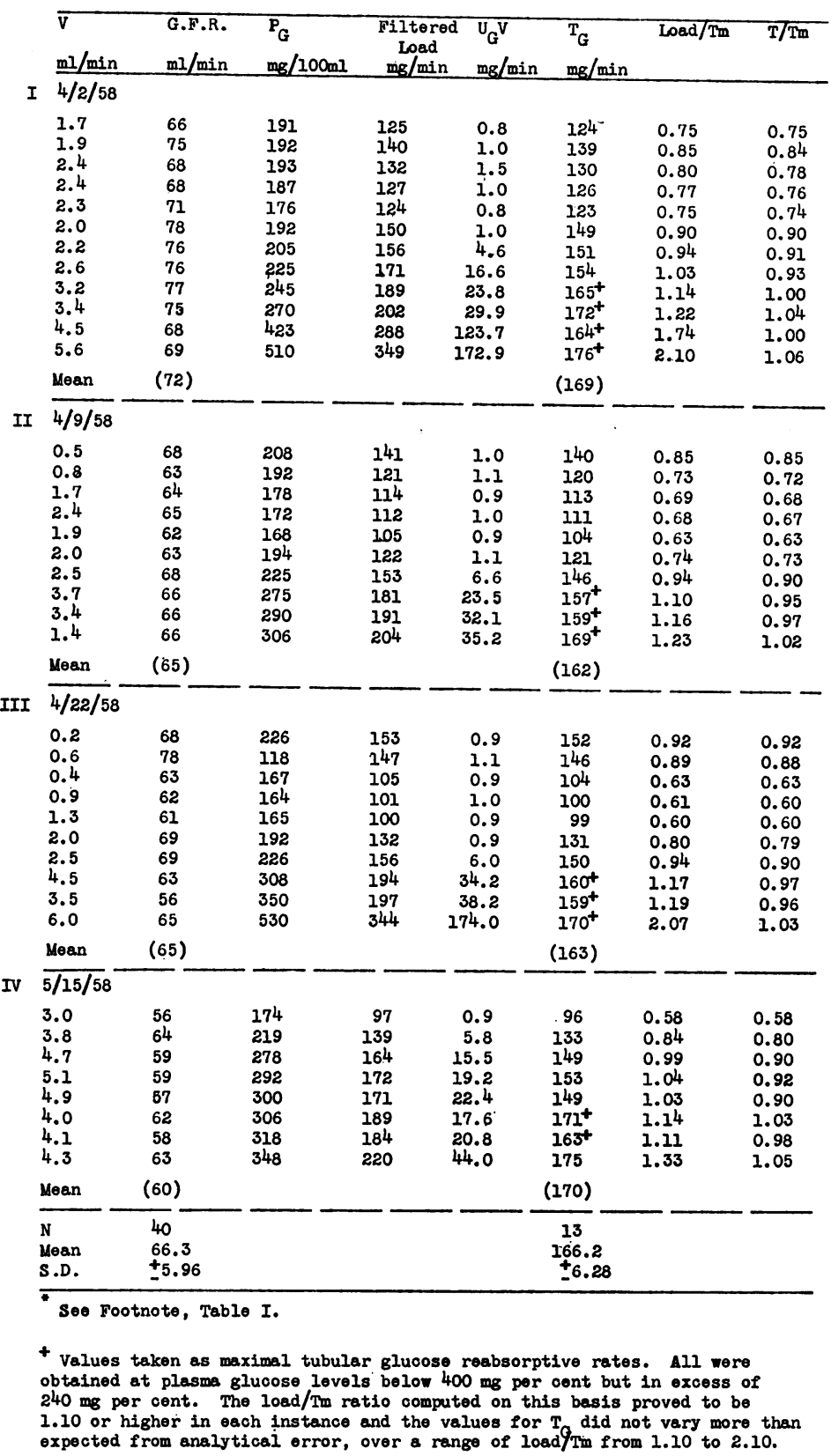

and 8.3 per cent, respectively. The values for glucose $\mathrm{Tm}$ obtained toward the close of nearly every test varied even less, in Dali averaging $369.8 \pm 19.74 \mathrm{mg}$ per minute; in Cora, $227.5 \pm$ 7.99 ; in Elena, $166.2 \pm 6.28$. Urine flow varied less during measurement of the Tm, although conditions were such as to augment rather than mini- mize inconstancy, since fatigue and restlessness tended to develop after several hours of recumbency, blood sampling, and urine collections. The high urine flows arising from the glucose osmotic diuresis may have been associated with a slight increase in inulin clearance in some experiments such as III in Cora (Table I) or V in Dali 
(Table II). In other experiments, however, the clearance tended to fall or varied to approximately the same extent at both high and low values for urine flow and glucose excretion. It may be concluded therefore that glomerular function remained relatively constant throughout these studies and that the relationship between glucose loading and reabsorption was not greatly affected by fluctuations in filtration.

The glucose transfer maximum was determined as frequently as possible in each animal at relatively high and constant plasma glucose concentrations. To assure saturation of the reabsorptive mechanisms, values were taken for $\mathrm{Tm}$ in Cora and Dali only when the plasma concentration was $400 \mathrm{mg}$ per $100 \mathrm{ml}$ or higher. Such levels were never attained in Elena, but the higher filtration rate/Tm ratio made it possible to accept values obtained at lower concentrations. All figures for plasma glucose in excess of $240 \mathrm{mg}$ per $100 \mathrm{ml}$ were accepted for Elena because it was found that the filtered load exceeded transfer by 10 per cent or more for all values when this criterion was applied. A value for Tm computed from the two determinations made when the load was more than twice reabsorption (viz.: $173 \mathrm{mg} / \mathrm{min}$ ) did not differ significantly from the accepted value (166.2 $\mathrm{mg} / \mathrm{min}$ ). Constancy of blood concentration proved more difficult to assure. The circumstances varied somewhat in each animal. In Cora (Table I) a "discard" equilibrium period during which the blood level was allowed to stabilize preceded the last two collection periods in Experiment I, and the last period in Experiment II. A similar period of equilibration elapsed before the last period in Experiments II and V on Dali (Table II), the last two periods in Experiment I and the last period in Experiment III on Elena (Table III). Many of the other values included in the final computations of $\mathrm{Tm}$ were also obtained when plasma concentrations were changing relatively little (e.g., in Experiments III and IV on Cora, I and III on Dali, and II and IV on Elena; cf. Tables I to III). As noted under Methods, the figures for plasma glucose used in calculating filtered load were obtained by interpolating 2.5 minutes before the midpoint of each period as an approximate correction for delay in the movement of filtered glucose from the glomeruli to the bladder. As a rule this procedure is entirely satisfactory, but with rapidly changing levels, serious discrepancies could develop. On a rising plasma concentration curve, for example, the glucose output might be derived from filtrate formed at lower glucose levels than those used in the calculations of load if delay were longer than 2.5 minutes. As a result, the calculated values for reabsorption would be too high. With a rapidly falling concentration, the reverse would be true. There is no evidence in the data that this factor introduced a significant error in values for $\mathrm{Tm}$, but some uncertainty must always prevail regarding determinations made during a "titration."

Evaluation of the relationship between glucose load and reabsorption over a full range of plasma concentrations was achieved in each animal. Great difficulty was experienced, however, in obtaining adequate data between the so-called "glucose threshold" (the plasma concentration at which glucose excretion, $\mathrm{U}_{\mathrm{G}} \mathrm{V}$, Tables I to III, first occurred) and Tm levels. Some of these values, taken for the most part from rising curves, may be affected by a "delay" error which would operate to augment the departure (or splay) from the ideal relationship by yielding falsely low figures for transfer ( $\mathrm{T} / \mathrm{Tm}$ ) for any load (load/ $\mathrm{Tm})$. In all three dogs, the critical transition phase was quite narrow so that few intermediate points were obtainable. Nevertheless, splay was sufficiently characteristic in each to permit differentiation. In Cora, $\mathrm{Tm}$ was reached at load/ $\mathrm{Tm}$ ratios as low as 1.04 ; in Elena, 1.14 ; and in Dali, 1.18 ; i.e., values which indicated minimal relative departures from strict ideality of 4,14 , and 18 per cent, respectively. These unexpected differences among the dogs were both fortuitous and fortunate, since they made it possible to test more stringently structural-functional correlations, which will be dealt with at length below.

Renal structural parameters. The renal weights were closely correlated with body weights in this small series. Thus, Dali weighed 54.8 per cent more than Elena and her kidneys weighed 58.5 per cent more than Elena's. Cora fell between these extremes in conformity with her size. The ratios between renal mass (twice the weight of the left kidney) and body weight were 4.9, 4.4, and $4.8 \mathrm{~g}$ per $\mathrm{kg}$ body weight in Dali, Cora, and Elena, respectively. The dimensions of the nephrons dissected from the left kidney obtained by 
nephrectomy in each animal are presented in Tables IV to VI and in Figures 1 and 2. These data indicate that dimensions of the average nephron also tended to vary with body size in showing a close correlation with renal weight in the three animals under study. In Dali, with the largest kidneys, the average surface area of the glomeruli and the average length and volume of the proximal convoluted tubules exceeded the average values of the same parameters in little Elena by $45,66.5$, and 38.5 per cent, respectively. The mean figure for glomerular surface in Cora fell between those of Dali and Elena but with respect to the other measurements, Cora and Elena

Table IV

Dimonsions of Glomeruili and Proximal Convolutions of Isolatod Nophrons "

Dog Core - Eidney Woight, $35.8 \mathrm{gm}$.

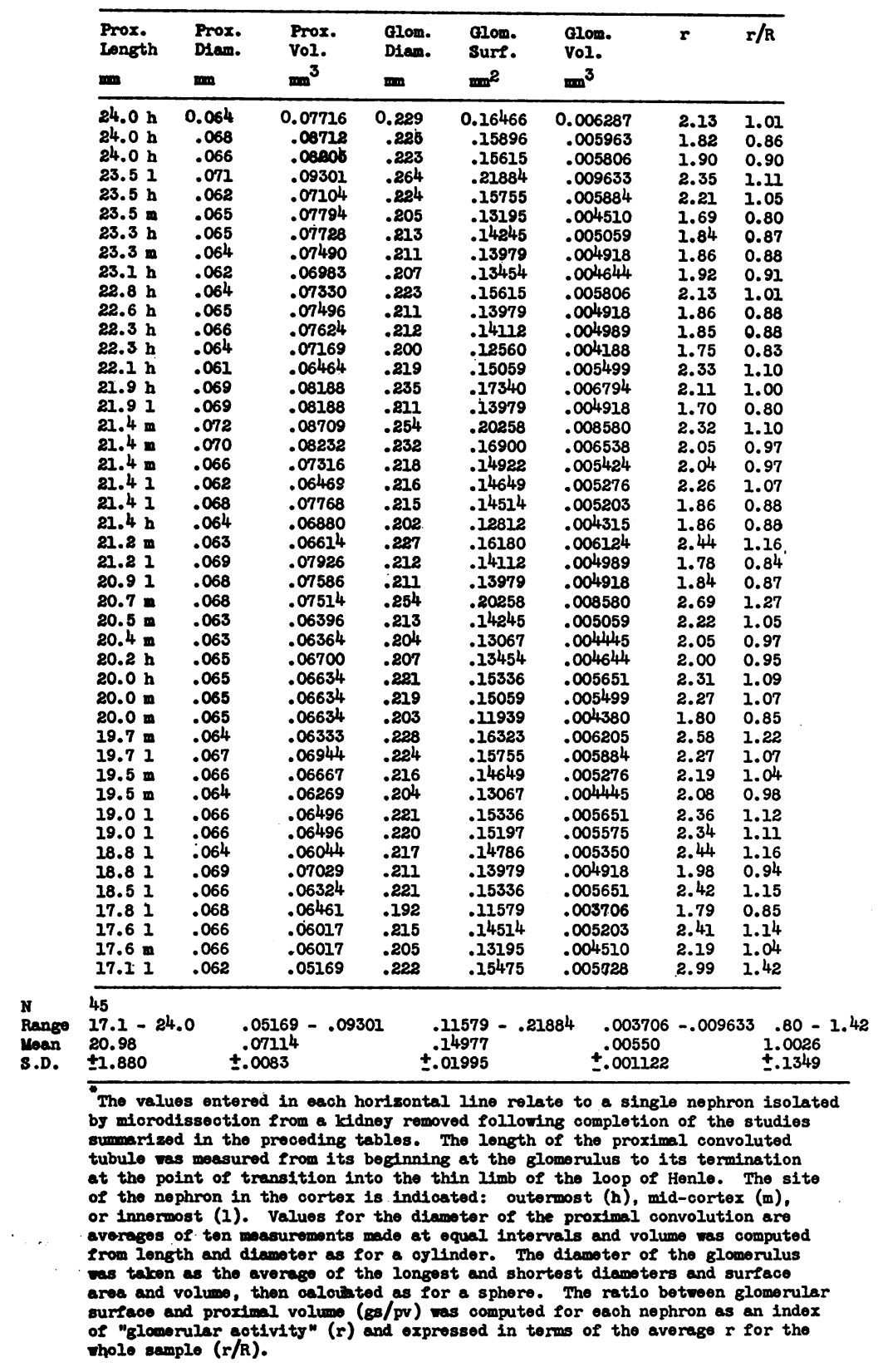




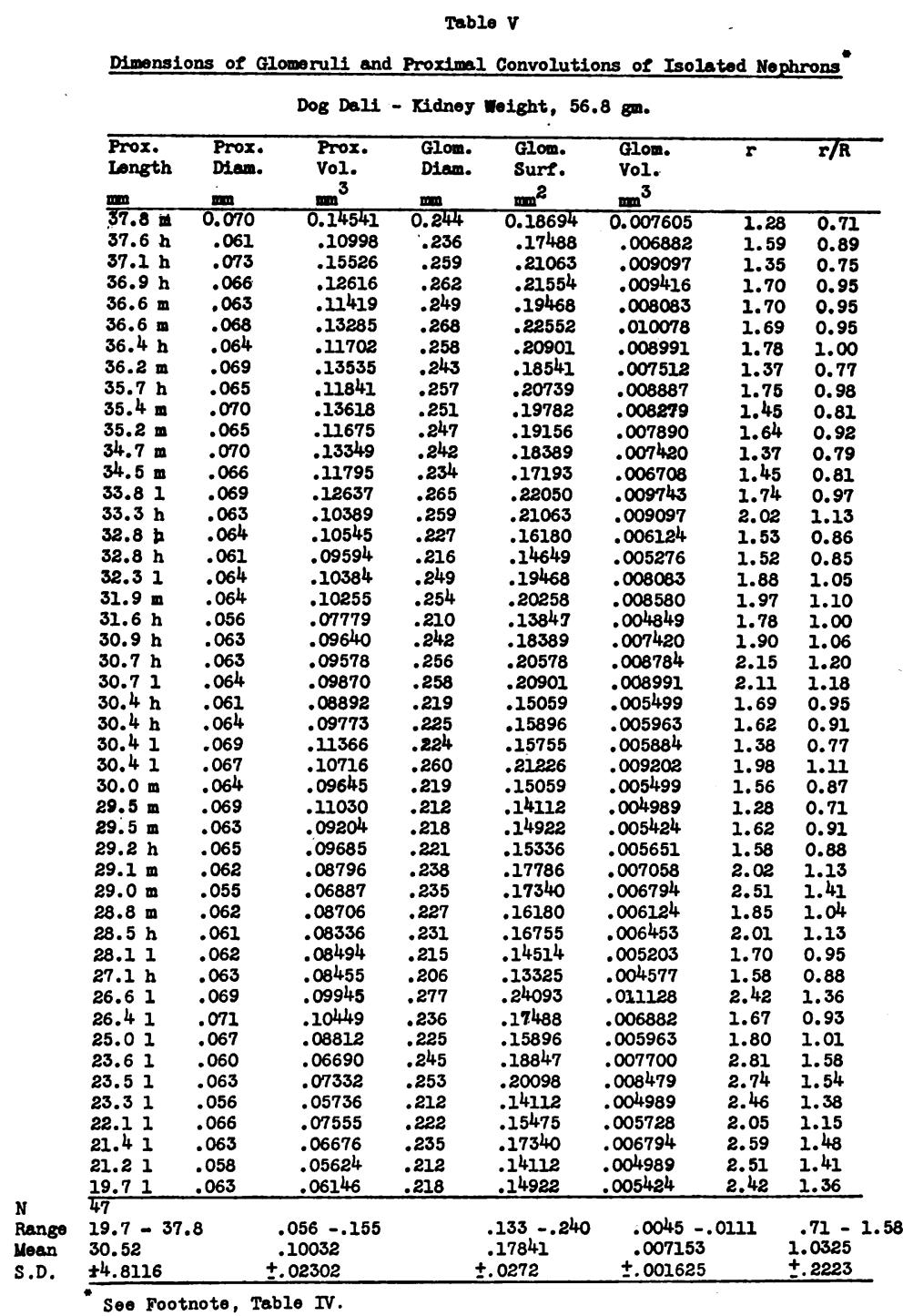

did not differ significantly. The tight correlation between nephron dimensions and renal mass in the three dogs is evident in the more or less equal values for ratios between mean glomerular surface and kidney weight $(0.0016,0.0018$, and $0.0017 \mathrm{~mm}^{2}$ per $\mathrm{g}$ for Dali, Cora, and Elena, respectively), mean proximal length and kidney weight $(0.269,0.253$, and $0.308 \mathrm{~mm}$ per $\mathrm{g})$, and mean proximal volume and kidney.weight $(0.00088$, 0.00085 , and $0.00084 \mathrm{~mm}^{3}$ per $\mathrm{g}$ ), computed in each instance for one kidney only.

Graphic comparison (Figure 1) of the measurements of proximal length, proximal volumes and glomerular surfaces indicates not only that all were larger, but also, that all ranged more widely in Dali. In general, the data were uniformly distributed about the means although proximal volume skewed toward the right in Elena. As in man (3), the length of the proximal convoluted tubules varied relatively less than any other dimension, and averaged $30.5 \pm 4.82 \mathrm{~mm}$ in Dali, $20.9 \pm 1.88 \mathrm{~mm}$ in Cora, and $22.0 \pm 2.34 \mathrm{~mm}$ in Elena. Proximal volume appeared to be somewhat more variable than proximal length in the dog and man, the coefficient of variation ranging from 11 to 28 per cent for dog and from 9 to 16 per cent for man (3). The average proximal volumes in the dogs $(0.100 \pm 0.028,0.071 \pm 0.008$, and 0.063 $\pm 0.14 \mathrm{~mm}^{3}$ in Dali, Cora, and Elena, respectively) were comparable with the average in man, $0.081 \pm$ 
$0.0196 \mathrm{~mm}^{3}$ (3). The glomerular dimensions, on the other hand, were much smaller in the dogs ; e.g., $0.178 \pm 0.027,0.149 \pm 0.020$, and $0.123 \pm$ $0.026 \mathrm{~mm}^{2}$ were the average glomerular surfaces in Dali, Cora, and Elena, respectively, as compared with $0.257 \pm 0.071 \mathrm{~mm}^{2}$ in the human kidney. Glomerular volume in the dogs averaged $0.0072 \pm$ $0.0016, \quad 0.0055 \pm 0.0011$, and $0.0041 \pm 0.0013$ $\mathrm{mm}^{3}$ for the dogs in contrast to $0.0126 \pm 0.0052$ $\mathrm{mm}^{3}$ for man.

Correlation of measurements of glomerulus and proximal convoluted tubule from the same nephron in the samples obtained by microdissection from each canine kidney yielded results similar to those emerging from the earlier study of human kidneys
(3). The glomerular surfaces were more closely correlated with proximal volumes than with proximal lengths of the attached tubule. This relationship was highly significant in Cora and Dali $(\mathrm{p}<$ 0.001 ) and at the level of borderline significance in Elena $(p<0.05)$. Although every dimension exhibited a greater variation in Dali, the glomerulotubular structural correlation was much closer than in either of the other dogs. Both proximal tubular volume and length were significantly correlated in Dali's nephrons with glomerular surface and volume. Glomerular and proximal volumes were closely correlated in Cora but not in Elena. Proximal length failed to show any significant relationship with either of the glomerular measure-

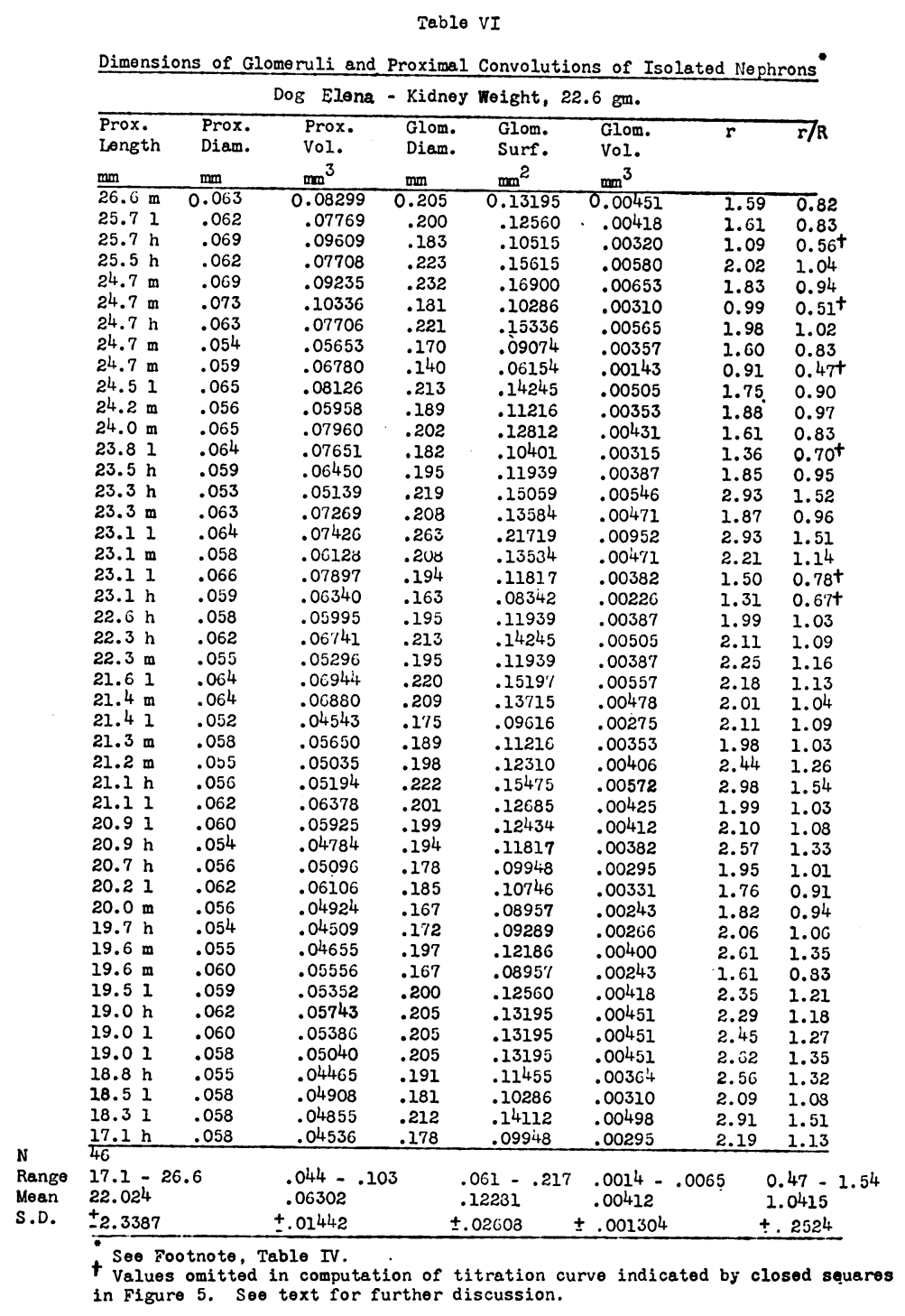


PROXIMAL LENGTH

GLOMERULAR SURFACE

PROXIMAL VOLUME
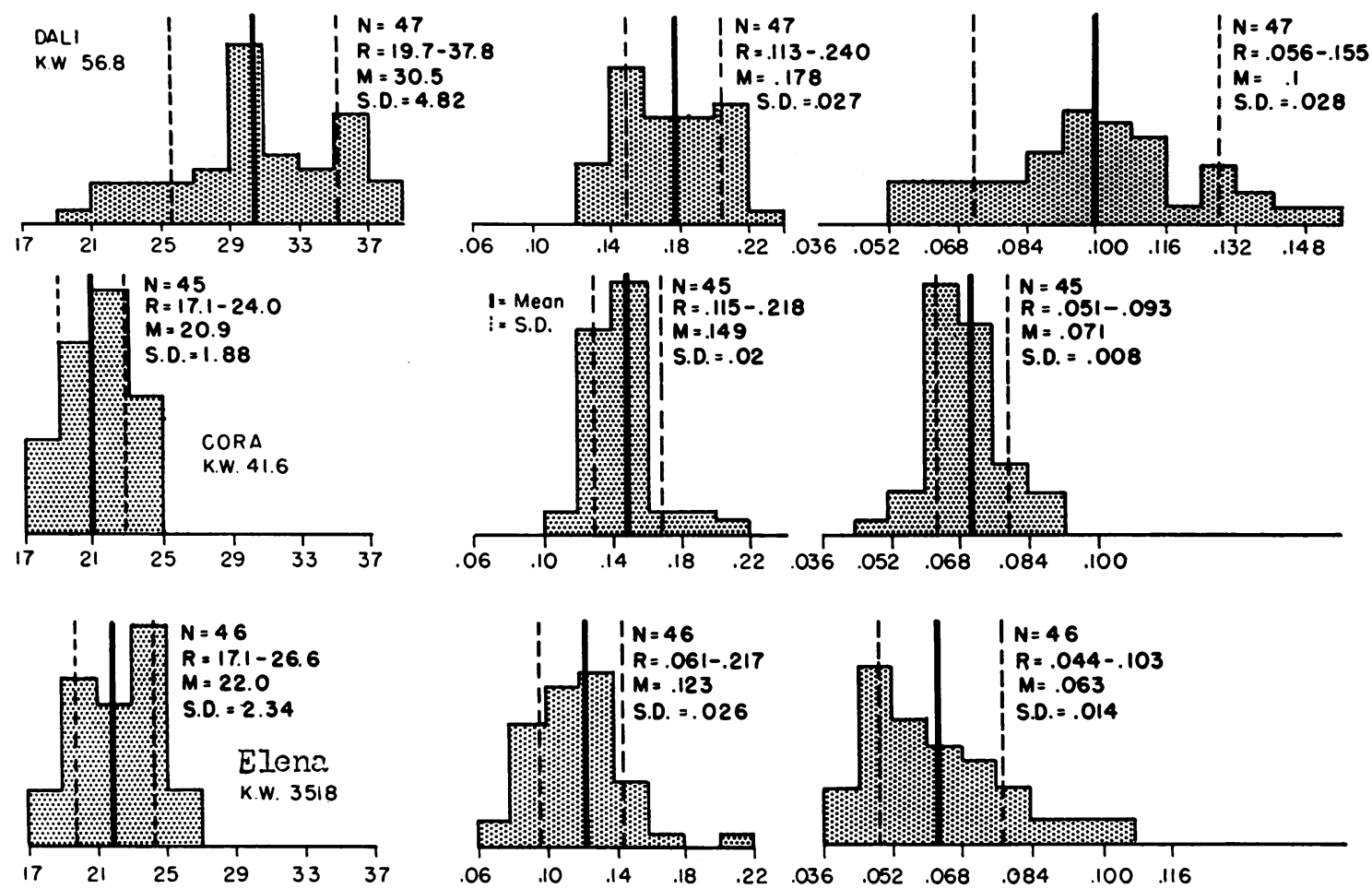

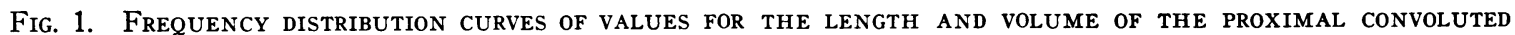
TUbUles AND FOR the SURface AREA of the glomeruli in three DOGS. The kidney weight (K.W.), means (M), and the number of nephrons measured $(\mathrm{N})$ are given for each animal (Dali, Cora, Elena), arranged in order of size from above down, and the ranges (R), means and standard deviation (S.D.) are presented for each measurement. The glomerular surfaces were computed as for a sphere, using the average of the longest and shortest diameters; the proximal volumes, as for a cylinder, using the average of 10 diameters taken at regular intervals along the course of the tubule.

ments in Cora and Elena. The relatively poor correlation between glomerular surface and proximal volume in Elena was strikingly improved by omitting the six nephrons in which the ratios ( $r$ ) between glomerular surface and proximal volume were excessively low (all 1.50 or less, $\dagger$ in Table $\mathrm{VI})$. With this exclusion the glomerular surface was significantly correlated with the proximal volume of the same tubule in Elena $(r=0.394, p<$ 0.01 ).

The character of these correlations between the glomerular surfaces and the volumes of their proximal convoluted tubules (using all values) is evident in the shapes of the ellipses, set out in Figure 2 , which have been drawn on the basis of the coefficients of correlation, means and standard deviations, to include approximately 70 per cent of the measurements $(2,9)$. The pooled data obtained in the study of three human kidneys (3) were em- ployed for the construction of a comparable ellipse defining the same parameters in man. The graphic presentation bears out the statistical derivatives in showing overlap between the three dogs and a tighter correlation (evident in relatively flat ellipses) between surface and volume for Cora and Dali than for Elena. Evident also is the extent to which man and dog differ with respect to mean values and range of glomerular surface areas and the relatively good agreement with respect to proximal convoluted tubular volumes. Further analysis of the data from the human kidneys in terms of each of the three individuals concerned would also yield three separate but overlapping ellipses like those derived from the canine data. Data on function for the same kidneys subjected to microdissection are unobtainable in man, however, and the pooled data must be used in computing structure and function. In both 


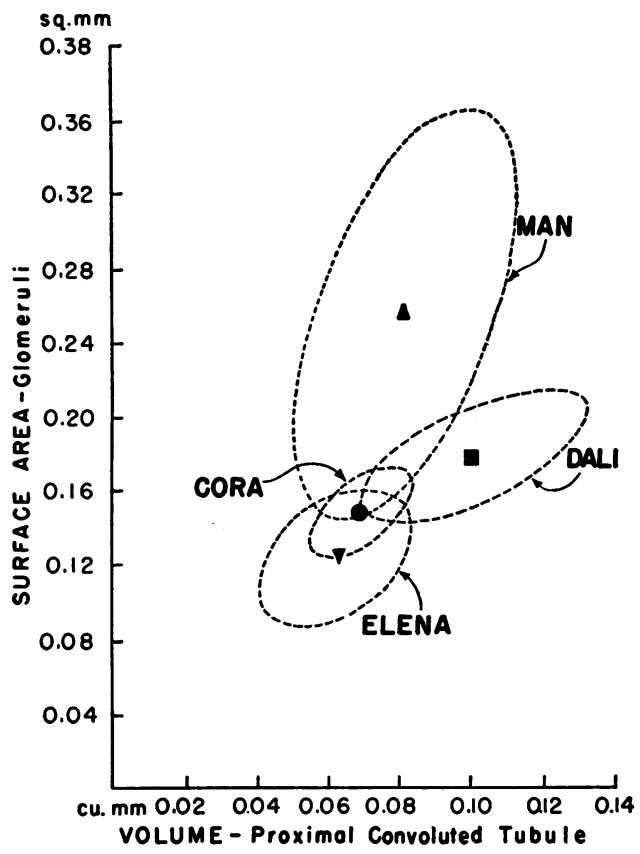

Fig. 2. Ellipses enclosing APPRoximately 70 PER CENT OF THE DATA FOR GLOMERULAR SURFACE AREAS AND THE VOLUME OF ATTACHED PROXIMAL VOLUMES IN MAN AND DOG. The values for man were taken from Oliver and MacDowell (3), and include measurements made on samples of nephrons (total, 104) from three human kidneys. The data for each dog are handled separately. The ellipses have been computed from the statistical parameters and the coefficient of correlation according to the method devised by Smith and co-workers (2) ; correct equations are given by Houck (9). Points for mean values are indicated at the center of each ellipse.

dog and man the external surface area of the glomerulus appears to be significantly correlated with the volume of the attached proximal convoluted tubule. Since other glomerulotubular measurements are not so closely correlated, the data appear to support the view that the functional balance between glomerulus and tubules can be expressed, in the first approximation, as the relationship between the glomerular surface and the proximal volume of each tubule.

Renal structural-functional correlation. At the outset, the proposed equation of glomerular surface area and glomerular filtration, and of proximal volume and glucose $\mathrm{Tm}$ may be tested for the kidney as a whole. The inulin clearance was found to vary proportionately with kidney weight (K.W.) ; it averaged $0.855 \mathrm{ml}$ per minute per $\mathrm{g}$ K.W. in Dali, 0.76 in Cora and 0.925 in Elena.
Glucose $\mathrm{Tm}$, also, changed in the same direction as renal mass but to a somewhat greater extent so that the ratio between $\mathrm{Tm}$ and kidney weight increased from $2.32 \mathrm{mg}$ per minute per $\mathrm{g} \mathrm{K}$.W. in Elena and 2.74 in Cora, to 3.25 in Dali. The relationship between the average volume of the proximal convoluted tubules and glucose Tm exhibited a similar phenomenon of rising values for $\mathrm{Tm} / \mathrm{pv}$ ratio: Elena 2.77, Cora 3.25, and Dali $3.70 \mathrm{~g}$ per minute per $\mathrm{mm}^{3}$. Glomerular surface and filtration were more closely related, since inulin clearance/glomerular surface area ratios were 546,422 , and $540 \mathrm{ml}$ per minute per $\mathrm{mm}^{2}$ in Dali, Cora, and Elena, respectively.

It should be noted that all these ratios have been computed in terms of a single nephron, rather than the total nephron population. The latter would be preferable, but total counts of glomeruli were not made in these kidneys and the number of nephrons involved is not available. If the figure given by Smith (10) from the data of Kunkel (11) and Vimtrup (12) -13,500 glomeruli per $\mathrm{g}$ of canine kidney weight-is accepted and applied, the $\mathrm{C}_{\text {In }} /$ total glomerular surface ratios equaled $0.00035,0.00037$, and $0.00055 \mathrm{ml}$ per minute per $\mathrm{mm}^{2}$, and the $\mathrm{Tm} /$ total proximal volume ratios equaled $0.0023,0.0028$, and $0.0027 \mathrm{mg}$ per minute per $\mathrm{mm}^{3}$ for Dali, Cora, and Elena, respectively. ${ }^{2}$ Calculated on either basis, a gross correlation between structural dimension and function is clearly apparent. A more exact comparison is made possible by accepting glomerular surface and proximal volume as structural equivalents of filtration and maximal glucose transfer.

In this view, the rate of filtration in any glomerulus may be taken as some function of the external surface of that glomerulus and expressed in terms of surface on the assumption that deter-

2 It has been noted above that the $\mathrm{Tm}$ of Dali was as large as that of a man weighing three times as much, yet Dali's kidney weight was only one-half as great as man's. These discrepancies disappear when total proximal volume in the two cases is compared: $153,360 \mathrm{cu}$ $\mathrm{mm}$ in Dali, and $172,883 \mathrm{cu} \mathrm{mm}$ in man. This observation indicates again (13) that gross kidney weight cannot be considered a proper correlate for many renal functions, since the latter, as in the present case of glucose reabsorption, may depend upon only certain portions (proximal convolutions) of the total nephrons, and these portions may be specifically variable within the totality of the "kidney." 
mining factors other than surface remain relatively constant throughout the kidney. Under these circumstances the percentage contribution of a single glomerulus to total filtration is equal to the percentage contribution of its surface area to the total glomerular surface area in the kidney. Since the sample of glomeruli measured may be taken to be a random sample, the summed glomerular surface of the sample (GS) may be accepted as representative of the entire kidney and

$$
c_{\text {in }} / C_{\text {In }}=g s / G S \text {. }
$$

Similarly,

$$
\mathrm{tm} / \mathrm{Tm}=\mathrm{pv} / \mathrm{PV}
$$

where $c_{\text {in }}$ is the filtration rate (nephron inulin clearance) in a single glomerulus (or category of glomeruli); $\mathrm{C}_{\mathrm{In}}$, total filtration rate or inulin clearance; gs, the external surface area of the glomerulus; and GS, the summed glomerular surface area of all the glomeruli measured, and where $\mathrm{tm}$ is the maximal glucose reabsorption rate of a single proximal tubule (or category of tubules); $\mathrm{Tm}$, the over-all glucose $\mathrm{Tm}$; pv, the volume of the proximal tubule, and PV, the summed proximal volumes in the sample. The glomerular activity for a single nephron $\left(r=c_{I n} / t m\right.$, where $c_{\text {in }}$ and $t m$ are functions of the same nephron) may then be expressed in terms of total activity $(R=$ $\mathrm{C}_{\mathrm{In}} / \mathrm{Tm}_{\mathrm{G}}$ )

$$
\frac{\mathrm{r}}{\mathrm{R}}=\frac{\mathrm{c}_{\text {in }} / \mathrm{tm}}{\mathrm{C}_{\mathrm{In}} / \mathrm{Tm}}=\frac{\mathrm{c}_{\mathrm{in}} / \mathrm{C}_{\text {In }}}{\mathrm{tm} / \mathrm{Tm}}=\frac{\mathrm{gs} / \mathrm{GS}}{\mathrm{pv} / \mathrm{PV}}
$$

provided gs and pv are measurements from a single nephron.

With this expression of structural-functional equivalence it is possible to derive the relationship between the filtered load of glucose and tubular reabsorption (the "titration curve") that would stem from any given nephron population and to compare the figures obtained by direct studies of function with those derived from dimensions. In constructing the theoretical titration curve, values for load/Tm ratios are computed arbitrarily at equal intervals (0.1) over a range of glomerular activities limited by the highest and lowest $r / R$ ratios for the given sample of nephrons (e.g., 0.80 to 1.42 for Cora, 0.71 to 1.58 for Dali, and 0.47 to 1.54 for Elena). Since the load of glucose at which the transfer system in any tubule is saturated and transfer rate reaches its maximum is just equal to $\mathrm{tm}$,

$$
\begin{gathered}
\mathrm{Pg} \times \mathrm{c}_{\text {in }}=\mathrm{tm}, \\
\mathrm{c}_{\text {in }} / \mathrm{tm}=1 / \mathrm{Pg}
\end{gathered}
$$

where $\mathrm{Pg}$ is the plasma glucose concentration at which the transfer system is just saturated, or $\mathrm{r} / \mathrm{R}=\frac{1 / \mathrm{Pg}}{\mathrm{C}_{\mathrm{In}} / \mathrm{Tm}}=\frac{1}{\mathrm{PgC}_{\mathrm{In}} / \mathrm{Tm}}=\frac{1}{\mathrm{load} / \mathrm{Tm}}$.

Thus the reciprocal of $r / R$ for any nephron is equivalent to the value of the filtered load (load/ $\mathrm{Tm}$ ratio) at which its transfer maximum is just reached. In practice, these values were computed at the midpoint of each class of measured nephrons, at intervals of 0.1 (e.g., for Cora the class intervals ran from 0.70 to $0.799,0.80$ to 0.899 , and so on, with load/Tm ratios computed at $0.75,0.85$, ...).

For each value of load/Tm, the corresponding value for $\mathrm{T} / \mathrm{Tm}$ that defines the titration curve may then be computed from the values for pv/PV. At any load/Tm below that at which all tubules are saturated, the total quantity of glucose reabsorbed each minute is a sum of 1 ) the amount removed by all the tubules saturated at that load ( $\mathrm{stm}$ ) and 2) the amount removed by the as yet unsaturated units $(\Sigma t)$. Thus, at any load,

$$
\mathrm{T} / \mathrm{Tm}=\left(\sum \mathrm{tm}+\sum \mathrm{t}\right) / \mathrm{Tm} .
$$

The slope of the titration curve at each point $(\Delta \mathrm{T} /$ $\Delta$ load $)$ is equal to the relative filtration rate $\left(c_{i n} /\right.$ $\mathrm{C}_{\mathrm{In}}$ ) in the unsaturated units in which all the glucose filtered is reabsorbed, because any change in reabsorption at that point can take place only in the unsaturated nephrons and because the change in reabsorption must be equal to a change in load. Thus

and

or

and

or

$$
\Delta \mathrm{T}=\Delta \mathrm{Pgc}_{\mathrm{in}}
$$

$$
\mathrm{c}_{\text {in }}=\Delta \mathrm{T} / \Delta \mathrm{Pg}
$$

$$
\text { or } \quad \operatorname{Pg} \Delta \mathrm{T} / \Delta \mathrm{Pg}=\sum \mathrm{t}
$$

and, multiplying by $\mathrm{C}_{\mathrm{In}} / \mathrm{C}_{\mathrm{In}}$ to express the result in terms of the load,

$$
\sum \mathrm{t}=\mathrm{PgC}_{\mathrm{ln}} \times \frac{\Delta \mathrm{T}}{\Delta \mathrm{PgC}_{\mathrm{In}}} .
$$




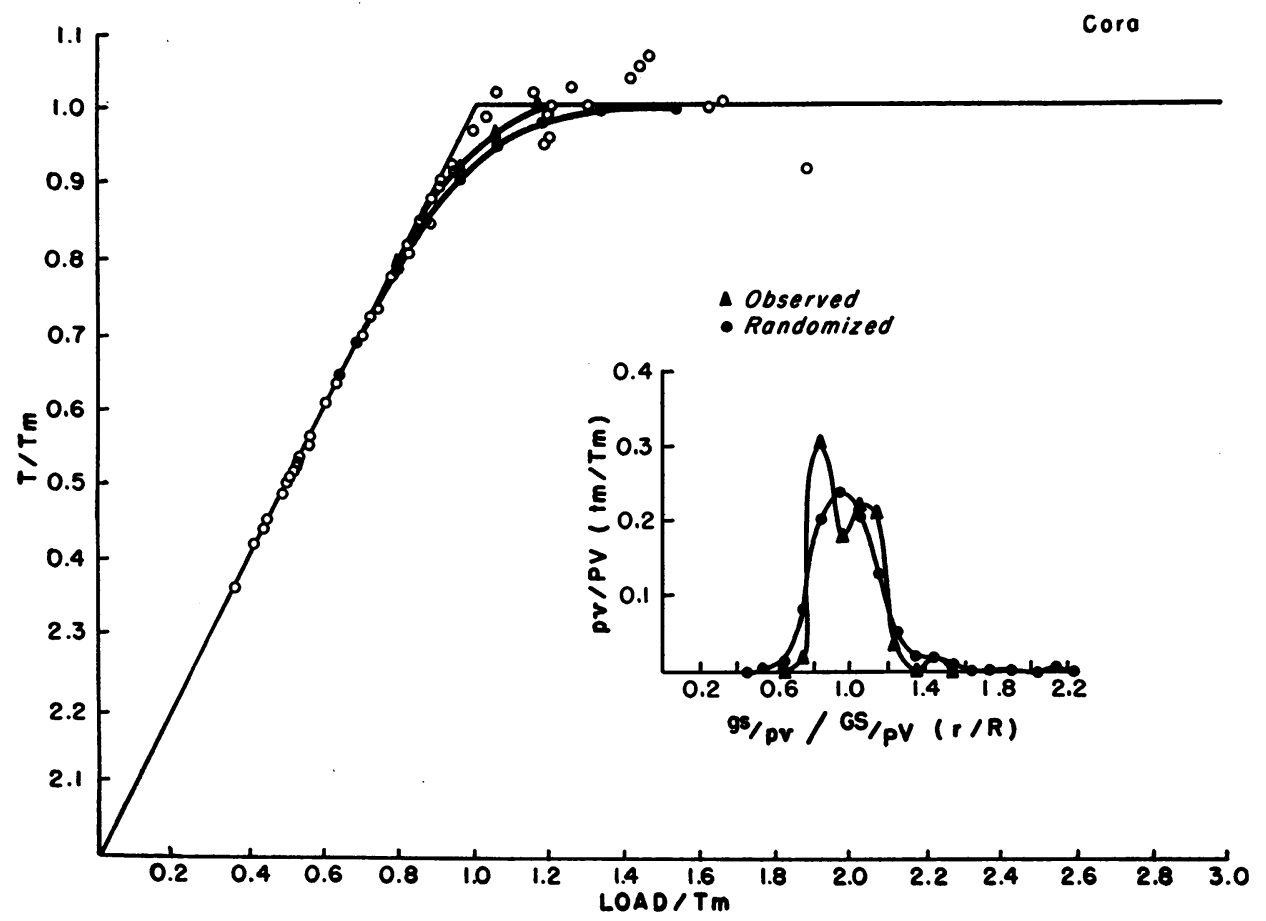

Fig. 3. Relationship between the tubular Reabsorption of glucose (T/TM) and the FILTERED GLUCOSE LOAD (LOAD/TM) IN CORA. The data obtained in the course of several studies of glucose transfer (Table I) are plotted here (open circles) in relation to relationship expected (straight lines) if the transfer maximal $(\mathrm{Tm})$ glucose reabsorption were reached in all nephrons at the same load. The curves indicate the relationships expected on the basis of the measurements of glomerular surface area (gs) and volume of the attached proximal convoluted tubule (pv). Both values are expressed in terms of the total surface area (GS) and proximal volume (PV), respectively. The ratio gs/pv, also expressed in terms of the total (gs/pv)/ $(\mathrm{GS} / \mathrm{PV})$, is taken as equivalent to the glomerular activity ( $r$, or the filtration rate in the glomerulus relative to the maximal glucose reabsorptive capacity for its attached proximal tubule- $\left.c_{\mathrm{in}} / \mathrm{tm}\right)$ and $(\mathrm{gs} / \mathrm{pv}) /(\mathrm{GS} / \mathrm{PV})$ as equivalent to $\mathrm{r} / \mathrm{R}$ or $\mathrm{c}_{\mathrm{in}} / \mathrm{tm} / \mathrm{C}_{\mathrm{In}} / \mathrm{Tm}$. The percentage contribution of each category of summed proximal volumes to the total (pv/PV) is taken as equivalent to $\mathrm{tm} / \mathrm{Tm}$. The distribution of glomerular activity (derived from the anatomical dimensions) among the nephron population (using pv/PV as measure of frequency) is plotted in the inset for the actual measurements (closed triangles) and the data for all possible values of glomerular activity (gs/pv) by using the measurements for gs and pv (closed circles, randomized). The glucose titration curves derived from these values are drawn above for comparison with the physiological data. It may be seen that the reabsorption per unit load fell between the relationships predicted for the ideal and the anatomical measurements.

Substituting, Equation 7 then becomes:

$$
\frac{\sum \mathrm{tm}}{\mathrm{Tm}}=\frac{\mathrm{T}}{\mathrm{Tm}}-\frac{\text { load }}{\mathrm{Tm}} \times \frac{\Delta \mathrm{T} / \mathrm{Tm}}{\Delta \text { load } / \mathrm{Tm}} .
$$

Equation 14 can now be derived from pv/PV since

$$
\frac{\sum \mathrm{tm}}{\mathrm{Tm}}=\frac{\sum \mathrm{pv}}{\mathrm{PV}}
$$

where $\mathrm{Spv}$ is the sum of the proximal volumes in all nephrons whose transfer systems are saturated.
The sum of proximal volumes in each class, defined by $r / R$ intervals, is thus added cumulatively to reach a total $\mathrm{\Sigma pv} / \mathrm{PV}$ value of 1.0 at $\mathrm{r} / \mathrm{R}$ corresponding to saturation of all nephrons or final Tm. In developing the titration curve from Equations 14 and 15, the first point is taken at the value of $r / R$ or load/Tm midpoint just below the lowest class of $r / R$ represented in the sample. At this point, load/Tm and $\mathrm{T} / \mathrm{Tm}$ are equal. The next value for $\mathrm{T} / \mathrm{Tm}$ can be derived by solu- 
tion of Equations 14 and 15 as follows:

$$
\begin{aligned}
\frac{\sum p v}{P V}=\frac{T_{1}}{T m}-\frac{\operatorname{load}_{1}}{T m} & \\
& \times \frac{\left(T_{2}-T_{1}\right) / T m}{\left(\operatorname{load}_{2}-\operatorname{load}_{1}\right) / T m}
\end{aligned}
$$

or (omitting $\mathrm{Tm}$ for simplicity of presentation, letting $\mathrm{L}$ stand for load/Tm ratio and $\mathrm{T}$ stand for $\mathrm{T} / \mathrm{Tm}$ ratio) :

$\mathrm{T}_{2}=\frac{\mathrm{T}_{1}\left[1+\mathrm{L}_{1} /\left(\mathrm{L}_{2}-\mathrm{L}_{1}\right)\right]-\sum \mathrm{pv} / \mathrm{PV}}{\mathrm{L}_{1} /\left(\mathrm{L}_{2}-\mathrm{L}_{1}\right)}$.

The value for $T_{2}$ thus computed becomes $T_{1}$ and $\mathrm{L}_{2}$ becomes $\mathrm{L}_{1}$ in analysis of the next higher interval. The full curve is built up for successively higher values of $\mathrm{Spv} / \mathrm{PV}$, as the proximal volumes in each class accumulate in the total up to PV (or $\mathrm{Tm})$.

In Figures 3 to 5 , the data for $\mathrm{T} / \mathrm{Tm}$ and load/ $\mathrm{Tm}$ are plotted for each animal. The ideal relationship-i.e., if all the filtered glucose were reabsorbed up to $\mathrm{Tm}$-is plotted in each figure as the straight line extending from the origin to the point at which both $\mathrm{T} / \mathrm{Tm}$ and load/Tm are equal to 1.0. In addition, the titration curve derived from the sample of nephrons obtained from each animal ("anatomical curve") is plotted as the curved unbroken line connecting closed triangles which arcs between the rising straight line of complete reabsorption and the Tm level. In each instance, the functional data tend to fall between the ideal and the anatomical curves, and in each instance the points tend to fall about $\mathrm{Tm}$ at values for load/Tm less than that at which the anatomical curve reaches $\mathrm{Tm}$. When the nephrons with the lowest values of $r / R$ for Elena (forming the peak to the left in the frequency distribution of $r / R$, Figure 5) are omitted from PV, a new anatomical curve could be derived (the curve connecting closed squares lying nearest the ideal, Figure 5) with which the functional data were found to conform closely. In general, then, predicted functional relationships agreed fairly well with those observed directly.

A frequency distribution curve has been set up for each population and presented in the figures

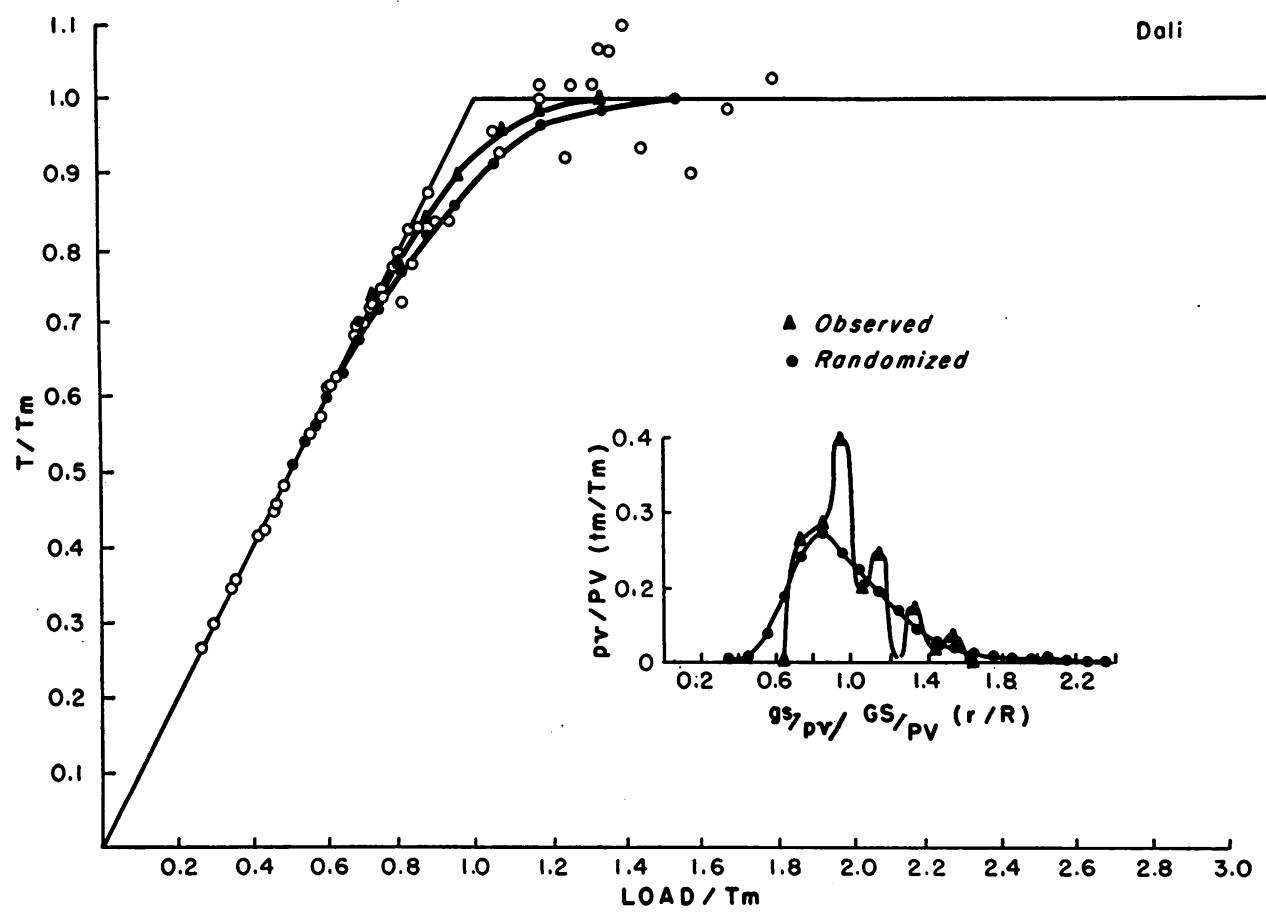

Fig. 4. Relationship between the tubular reabsorption of glucose (T/Tm) and the Filtered load of Glucose (loAd/TM) in Dali. See legend, Figure 3. The data are more widely scattered but indicate saturation of the transfer system at loads equivalent to or even less than those predicted from the anatomical data. 


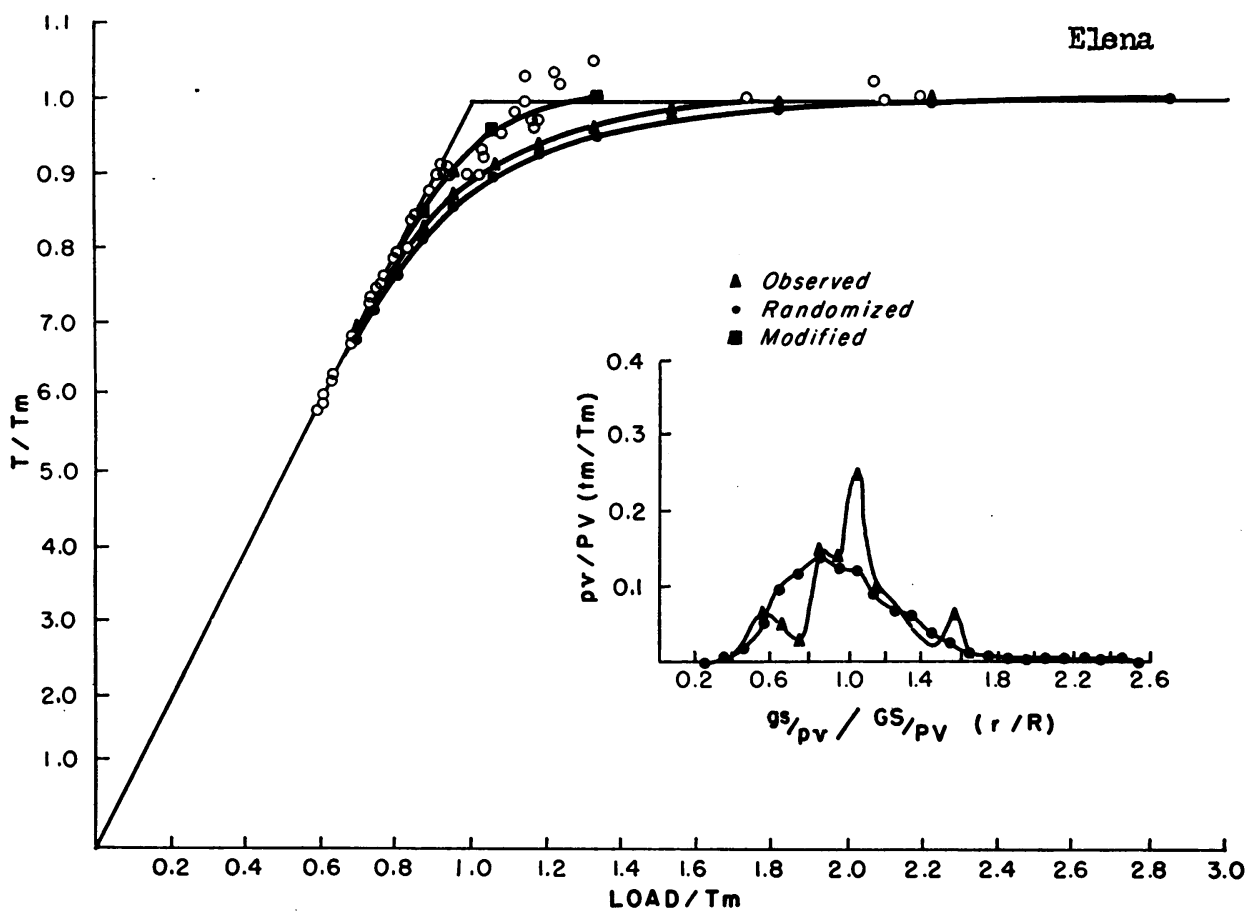

Fig. 5. Relationship between the tubular reabsorption of glucose (T/Tm) and the FILTERED LOAD OF GLUCOSE (LOAD/TM) IN Elena. See legend, Figure 3. There is relatively little difference between derived glucose titration curves from both observed and randomized nephron dimensions in conformity with the observation of a correlation between gs and $\mathrm{pv}$ of borderline significance. The physiological data fall about a curve derived from the observed dimensions after exclusion of the six measurements that account for the peak on the left of the distribution curves and that were characterized by low values for glomerular activity (closed squares).

with the data on glucose titration. The structural figures are summarized at $r / R$ ratios, and frequency is defined in terms of the percentage of the total summed proximal volumes found in each $r / R$ category. A smoothed curve is drawn between the points obtained by difference for each successive solution of Equation 17. As expected, the animals differed widely-from the broad flat three-peaked plot for Elena to the narrow doublehumped distribution for Cora-the anatomical curves reflecting in their deviation from ideal the spread in distribution.

To determine the extent to which an uncorrelated distribution of glomeruli and tubules would affect glucose titration, the data were randomized by computing all the $r / R$ ratios possible for each observed glomerular surface with the entire population of observed proximal volumes. The resulting population for each dog was then categorized in terms of $\mathrm{r} / \mathrm{R}$ classes. The total $\mathrm{pv}$ in each class was computed and expressed as a per- centage of the total ( $\mathrm{ppv} / \mathrm{PV})$. The random distribution curves thus obtained have been plotted in each of the figures. In Figure 3 (Cora) a single peaked and somewhat broader pattern results; an even greater discrepancy is evident in Figure 4 (Dali), but in Figure 5 (Elena) the major change has been elimination of the peaks and a somewhat more marked skewing to the right. The titration curves derived from the randomized data (closed circles) differ similarly. The random and observed curves lie close together in Figure 3 (Cora) because the difference between them, although it is significant, is minimized by the modest departure of the observed data from the hypothetical relationship. A much greater difference is clearly evident for Dali (Figure 4) whereas the two lines are practically superimposable in Figure 5 (Elena). The functional data from the study of Cora clearly tend to fall within the area bounded by the ideal and anatomical curves; from the study of Dali, about both the anatomical and random 
curves; and from Elena, much closer to the ideal and about a theoretical curve derived from the anatomical data after exclusion of the nephrons with very low activity ratios.

\section{DISCUSSION}

The results of this study indicate that in the dog, as in man (3), glomerular surface area is significantly correlated with the volume of the proximal convoluted tubule. In view of the physiological evidence (2) this correlation can be interpreted as the structural manifestation of "glomerulotubular balance." Hence, glomerular surface and proximal volume may be accepted as reasonable structural equivalents of glomerular filtration rate and maximal tubular reabsorption of glucose, respectively. On this basis it has been possible to compare data on function obtained in the intact dog with derivative values of "function" from measurements of nephrons dissected from a kidney of the same animal removed on completion of the physiological studies. Glucose titration curves so derived closely followed the data obtained previously on glucose reabsorption and loading. The tendency for all of the tubules to reach transfer saturation at approximately the same plasma glucose concentration may be attributed in part to a structural proportionality between the glomerulus and the proximal convoluted tubule of each nephron that tends to minimize populational heterogeneity. Analysis of the data indicates that this structural balance between glomeruli and proximal convolutions is not the only, or even necessarily the most important, factor concerned in the observed correlation of the structural and functional findings. Even when one proceeds on the assumption that no functionally significant relationship exists between the two dimensions, and the structural data are "randomized" by computing the spread in all possible surface/volume ratios within each sample of nephrons, the derived titration curves do not differ greatly from those calculated from the actual related structural values. Thus, it is evident that functional heterogeneity is limited to some extent also by a relative lack of structural variety, at least so far as glomeruli and proximal convolutions are concerned.

Certainly, the structural-functional equivalents employed are not strictly valid as a complete description of the physiological processes concerned; in the present state of our knowledge, assumptions must be made. In the case of filtration, the details of the passage through a series of capillary, basement and epithelial membranes are at present unknown. A precise measurement of the surface area involved in filtration is impossible. The external surface of the tuft across which filtration must eventually occur is not easily subjected to direct measurement, since foldings and other irregular features result in a much larger potential surface than that which would be provided by a perfect spherical or globular structure. At best, therefore, only a rough estimate of the surface of the filtration barriers may be made on the assumption that the glomerulus is a sphere. Measurement of the dimension of the proximal convoluted tubule is less difficult. The volume of the proximal convolution (exclusive of its lumen) may be equated with glucose Tm on the assumption that maximal reabsorption is a function of cell mass. The search for other structural correlations between glomeruli and the attached tubules was unrewarding. Neither glomerular surface nor volume was significantly correlated with proximal tubular length. The proximal volume failed to show a correlation with glomerular volume. Other dimensions of theoretical values, such as the internal surfaces of the tubules and the total glomerular capillary surfaces, were not accessible to measurement.

In addition to the uniformity resulting from the structural correlation between glomeruli and proximal convolutions or from a relatively restricted dimensional variability, a third factor of functional adaptation must be taken into account. In Elena, the data obtained in the study of function showed much less splay than the curves derived from the anatomical measurements. The excellent agreement obtained by omission of a small fraction of "relatively inactive" (i.e., low gs/pv ratios) nephrons may indicate that the large proximal volumes in nephrons of this category possess relatively less intracellular substance devoted to glucose transfer (or more nonactive material such as fat, glycogen or protein), that the relatively small glomeruli present a large filtering surface not included in surface measurements, or both. If so, determination of the appropriate structuralfunctional equivalents would resolve the difficulty. 
On the other hand it is possible that physiological adjustments not readily susceptible to structural expression may be involved. A relatively high filtration pressure as a result of a lower afferent arteriolar resistance could easily result in a higher filtration rate per unit surface area. Or interference with glucose transportation-as, for example, by phlorhizin - could increase the ratio between filtration and tubular transfer maximum. To what extent these factors may operate remains uncertain, but it appears likely that heterogeneity would be as often enhanced by them as minimized. Moreover, as noted above, the necessary assumptions in this work, viz.: 1) that glomerular filtration pressure is everywhere the same, and 2) that cellular mass bears some constant relationship to cellular metabolic function, seem warranted on the evidence.

In all three dogs the population of glomeruli and proximal tubules appeared to be distributed randomly throughout the cortex with respect to size. This observation implies that in every nephron at any level in the cortex, from the capsule to the medulla, the distal portion of the tubule receives, on the average, residual filtrate in the same volume and with the same composition. Any differences in composition of urine entering the collecting ducts from different nephrons may be ascribed, therefore, to the marked anatomical heterogeneity of the loops of Henle and the distal convoluted tubules rather than to heterogeneity of the glomeruli and proximal tubules.

\section{SUMMARY}

Correlation of the structure and the function of the glomeruli and their attached proximal convoluted tubules has been investigated in three normal female dogs. The activity of the glomeruli in providing by filtration a load of glucose for reabsorption by the proximal convoluted tubules was evaluated in each animal over a wide range of arterial glucose concentrations. The "glucose titration curve" (or the relationship between tubular reabsorption and filtered load) so obtained is determined by the distribution of glomerular activity (the filtration rate of a glomerulus relative to the maximal rate of glucose reabsorption of which its proximal convoluted tubule is capable) in the nephron population. When sufficient func- tional data had been obtained, one kidney was removed from each dog and a sample of from 45 to 47 nephrons obtained by microdissection. The values for glomerular surface (calculated as for a sphere from the average of the greatest and least diameters) and for the volume of the attached proximal convoluted tubule (calculated as for a cylinder using the length and the average of 10 diameters measured at regular intervals) were more closely correlated $(\mathrm{p}<0.001$ in two dogs, Cora and Dali, and p $<0.05$ in one, Elena) than any of the other glomerulotubular dimensions. Taking glomerular surface (gs) as a "structural equivalent" of filtration, and proximal volume (pv) as that of the maximal glucose reabsorptive capacity of the attached proximal convolutions, the glomerular activity for each nephron could be computed in anatomical terms as gs/pv. "Glucose titration curves" derived from the anatomical data closely fitted the functional data in Cora and Dali and, if allowance were made for a small number of very "inactive" nephrons, also in Elena. The agreement between the data appears to be consistent with the validity of the basic assumptions that glomerular filtration rate is determined by the area of the external surface of the capillary tuft and that maximal glucose reabsorptive capacity depends upon the mass of proximal convoluted tubular cells. The findings also indicate that the tendency for the reabsorptive mechanism in all nephrons to be saturated at approximately the same plasma glucose concentration, with minimal "splay" in the titration curve, can be ascribed in part, as previously predicted by Smith and coworkers (2), to a structural balance between glomeruli and tubules. Splay is also minimized, however, by a central tendency of the anatomical data that is expressed as a relatively small coefficient of variation.

\section{ACKNOWLEDGMENT}

The authors wish to express their appreciation for the technical assistance of Mrs. Sally Mancusi-Ungaro and Susan Stassa, and Miss Evelyn Audioun.

\section{REFERENCES}

1. Bradley, S. E., and Wheeler, H. O. On the diversities of structure, perfusion and function of the nephron population. Amer. J. Med. 1958, 24, 692. 
2. Smith, H. W., Goldring, W., Chasis, H., Ranges, H. A., and Bradley, S. E. The application of saturation methods to the study of glomerular and tubular function in the human kidney. J. Mt Sinai Hosp. 1943, 10, 59.

3. Oliver, J., and MacDowell, M. The structural and functional aspects of the handling of glucose by the nephrons and the kidney and their correlation by means of structural-functional equivalents. J. clin. Invest. 1961, 40, 1093.

4. Bradley, S. E., Bradley, G. P., Tyson, C. J., Curry, J. J., and Blake, W. D. Renal function in renal diseases. Amer. J. Med. 1950, 9, 766.

5. Walker, A. M., and Bott, P. A.; Oliver, J., and MacDowell, M. The collection and analysis of fluid from single nephrons of the mammalian kidney. Amer. J. Physiol. 1941, 134, 580.

6. Fujita, A., and Iwatake, D. Bestimmung des echten Blutzuckers ohne Hefe. Biochem. Z. 1931, $242,43$.

7. Harrison, H. E. A modification of the diphenylamine method for determination of inulin. Proc. Soc. exp. Biol. (N. Y.) 1942, 49, 111.

8. Nelson, N. A photometric adaptation of the Somogyi method for the determination of glucose. J. biol. Chem. 1944, 153, 375.

9. Houck, C. R. Statistical analysis of filtration rate and effective renal plasma flow related to weight and surface area in dogs. Amer. J. Physiol. 1948, 153, 169.

10. Smith, H. W. The Kidney: Structure and Function in Health and Disease. New York, Oxford Univ. Press, 1951.

11. Kunkel, P. A., Jr. The number and size of the glomeruli in the kidney of several mammals. Bull. Johns Hopk. Hosp. 1930, 47, 285.

12. Vimtrup, $B$. On the number, shape, structure, and surface area of the glomeruli in the kidneys of man and mammals. Amer. J. Anat. 1928, 41, 123.

13. Oliver, $J$. The regulation of renal activity. $X$. The morphologic study. Arch intern. Med. 1924, 34, 258.

\section{SPECIAL NOTICE TO SUBSCRIBERS}

Post Offices will no longer forward the Journal when you move.

Please notify The Journal of Clinical Investigation, Business

Office, 333 Cedar Street, New Haven 11, Conn., at once when you have a change of address, and do not omit the zone number if there is one. 